\title{
Correction to: Activity patterns in the reintroduced Pyrenean brown bear population
}

\author{
Aida Parres ${ }^{1}$ (D) - Santiago Palazón ${ }^{2}$ • Ivan Afonso ${ }^{3}$ • Pierre-Yves Quenette ${ }^{4}$ - Antoni Batet ${ }^{2}$. Jean-Jacques Camarra ${ }^{4}$. \\ Xavier Garreta ${ }^{5}$. Salvador Gonçalves ${ }^{3}$ • Jordi Guillén ${ }^{5}$ • Sergio Mir ${ }^{3}$ • Ramón Jato ${ }^{6}$ - Joan Rodríguez ${ }^{3}$. \\ Jerome Sentilles ${ }^{4}$ - Laura Xicola ${ }^{7}$. Yolanda Melero ${ }^{8}$
}

Published online: 14 July 2020

(C) Mammal Research Institute, Polish Academy of Sciences, Bialowieza, Poland 2020

Correction to: Mammal Research (2020) 65:435-444 https://doi.org/10.1007/s13364-020-00507-w

The publisher regret that the presentation of Fig. 3 in the original version of the above article was incorrectly presented. The data in the image were inadvertently omitted during publication process. The correct Fig. 3 is shown as follows:

Publisher's note Springer Nature remains neutral with regard to jurisdictional claims in published maps and institutional affiliations.
The online version of the original article can be found at https://doi.org/10. 1007/s13364-020-00507-w

Aida Parres

aida@iop.krakow.pl

Institute of Nature Conservation, Polish Academy of Sciences, Adama Mickiewicza 33, 31120 Cracow, Poland

2 Regional Government of Catalonia, 08017 Barcelona, Spain

3 General Council of Aran (Conselh Generau d'Aran), 25530 Vielha, Lleida, Spain
4 French Agency of Biodiversity, OFB (Office Français de la Biodiversité), 31800 Villeneuve de Rivière, France

5 Brown Bear Foundation, FOP (Fundación Oso Pardo), 39010 Santander, Spain

6 Aragonese Society for Agri-environmental Management (Sociedad Aragonesa de Gestión Agroambiental), 50018 Zaragoza, Spain

7 Autonomous University of Barcelona, 08193 Cerdanyola del Vallès, Spain

8 CREAF, 08193 Cerdanyola del Vallès, Spain 


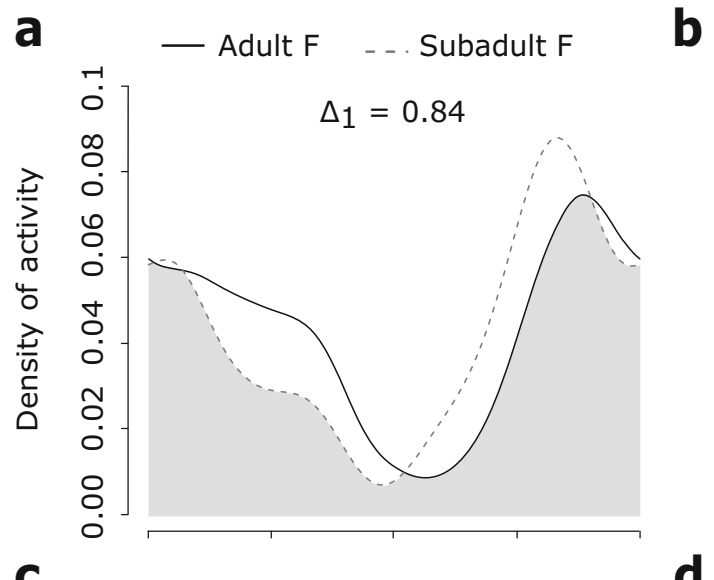

b $\quad$ - Adult F $\quad \cdots$ Subadult M
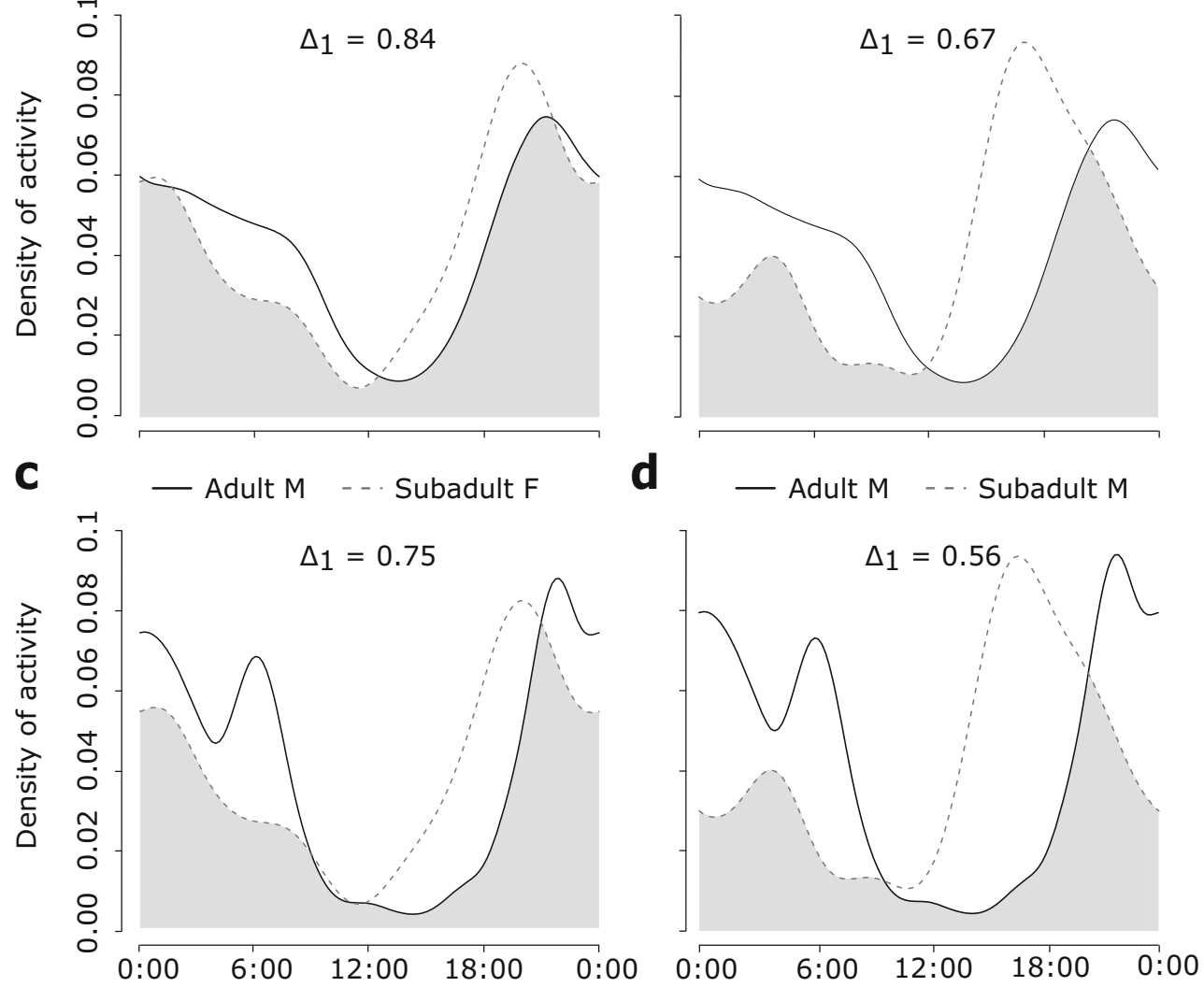

Fig. 3 General brown bear activity pattern and overlapping activity analysis $\left(\Delta_{1}\right)$ in relation to the sex-age group: a adult females vs. subadult females, $\mathbf{b}$ adult females vs. subadult males, $\mathbf{c}$ adult males vs.

indicate adults and dotted lines indicate subadults. The activity records for each sex-age group were $\mathrm{n}_{\text {Adult } \mathrm{F}}=373 ; \mathrm{n}_{\text {Adult } \mathrm{M}}=739 ; \mathrm{n}_{\text {Subadult } \mathrm{F}}$ $=52 ; \mathrm{n}_{\text {Subadult } \mathrm{M}}=25$ 